\title{
OS VIKINGS E O ESTEREÓTIPO DO BÁRBARO NO ENSINO DE HISTÓRIA
}

Johnni Langer*

RESUMO:

O artigo procura refletir sobre o bárbaro no ensino de História, propondo alguns elementos para a crítica dos estereótipos.

PALAVRAS-CHAVE:

Civilização Viking, estereótipo, ensino de História.

"O Viking não pode ser considerado hoje irrelevante no desenvolvimento da nossa civilização, pois os méritos da sua arte, cheia de força e ritmo, patenteando uma firme aceitação das limitações impostas pelos materiais a utilizar, são mais perceptíveis para nós, agora, do que o foram para os nossos antepassados". Holger Arbman (Os Vikings, 1967.)

$O$ mundo em que vivemos atualmente encontra-se repleto de imagens fantasiosas sobre o passado, estereótipos muito bem estruturados na sociedade que dificilmente conseguem ser eliminados. Em especial as representações relacionadas com a História, que Elias Tomé Saliba denomina de "imagens canônicas", proliferam em grande quantidade nos manuais didáticos. Apresentamos aqui uma análise sobre um caso especial, envolvendo a figura do bárbaro escandinavo ${ }^{1}$ da Idade Média, no qual inicialmente apresentamos alguns

* Doutor em História pela UFPR. Professor da Unespar (União da Vitória, PR) e Facipal (Palmas, PR). Editor do boletim Notícias Asgardianas.

1 Aqui utilizamos as palavras Viking, nórdico e escandinavo como sinônimos. Diferenciações étnicas regionais, no caso dos Vikings dinamarqueses, alemães, noruegueses, suecos, russos ou irlandeses não serão considerados. 
parâmetros conceituais, e em seguida abordamos um experimento didático envolvendo o tema.

\section{O estereótipo do Viking}

O primeiro aspecto do estereótipo a respeito dos escandinavos é o seu equipamento de guerra. No imaginário moderno, a palavra imediatamente associa-se a guerreiros portando capacetes com enormes chifres laterais. Nada mais falso, aos olhos da arqueologia e da historiografia medieval. Dois séculos de investigação acadêmica demonstraram que nunca existiu qualquer tipo de vestígio material que confirmasse essa imagem. Nem mesmo durante a Idade Média os Vikings eram representados dessa maneira, na visão de outros povos. O estereótipo surgiu no início do século XIX, em conseqüência da idealização romântica do bárbaro, utilizado como suporte para a constituição de diversas nacionalidades oitocentistas (LANGER, 2001). Diversos pintores representaram cornos não somente nos nórdicos medievais como também em seus deuses, que tornaram-se muito populares a partir de então.

$\mathrm{O}$ advento do século XX trouxe a novidade da cultura de massa. Dois veículos em especial, as histórias em quadrinhos e o cinema, popularizariam ao extremo essas fantasias. Em 1937 o público viu o surgimento do famoso quadrinho Prince Valiant, de Harold Foster, um cavaleiro descendente de Vikings, mas que juntamente com o rei Arthur e seus ingleses, combatem a invasão de maléficos escandinavos. Em toda essa obra, o invasor Viking possui o estatuto de bárbaro estrangeiro, trazendo a desordem, o caos aos bons princípios da cavalaria britânica. E é claro, com sua enorme estatura, ferocidade e seus possantes 
elmos com cornos e asas. A série foi publicada em jornais dominicais, nunca em tiras, e dispensando o uso de balóes. Outros quadrinhos trataram de solidificar o imaginário clássico dos escandinavos: Asterix (1959); El capitan Trueno (1960); Thor (1962); Eric the Noorman (1962), Erik, the Viking (1965). Uma série em especial, tornou-se responsável pela continuidade do estereótipo: Hagar, o horrivel (1965).

Criado pelo norte-americano Dik Browne, até hoje apresenta-se como um dos maiores sucessos de tiras humorísticas em jornais de todo o mundo. Hagar é um Viking barbudo, gordo, relaxado e beberrão, que como todos os seus conterrâneos nórdicos, vive de saques, pilhagens e aventuras pelo mundo medieval. Assim como seu filho Hamlet, sua esposa Helga e seu cachorro Snert, Hagar porta um elmo com grandes cornos. Já sua filha Honi, sempre veste-se com um elmo com asas laterais e malhas peitorais de ferro - uma inspiração direta no modelo operístico do século XIX. Atualmente o personagem é publicado diariamente em muitos periódicos brasileiros, como Gazeta do Povo e Folha de São Paulo, além de diversos álbuns especiais que circulam em bancas de jornais, como os quadrinhos de bolso lançados pela editora Ópera Graphica de São Paulo em 2002.

O cinema também influiu decisivamente para a expansão da imagem fantasiosa. Filmes como Conan, o bárbaro (1983); O Viking (1978); A lenda de um guerreiro (2001), contribuíram para reforçar a impressão perante o grande público, de que os guerreiros da Antigüidade e Idade Média utilizavam freqüentemente equipamentos córneos, além de transmitir elementos de insociabilidade e transgressão civilizatória.

O segundo aspecto do estereótipo é a identificação dos escandinavos com seres impiedosos, piratas pagãos e cruéis, verdadeiros flagelos de Deus enviados para redimir os pecados 
dos cristãos, ou bestas selvagens que se opõe ao avanço da civilização cristã. Na realidade aqui temos uma continuidade de outro estereótipo muito mais antigo e que se mescla ao dos escandinavos: a imagem do bárbaro. Originalmente criada para diferenciar os povos de línguas estranhas ao mundo clássico, com o tempo transforma-se em identificação com todos aqueles que não eram cristianizados, e portanto, colocavam-se fora dos ideais de civilidade e comportamento (RAMINELLI, 1996, p. 53). A questão de violência é um tema tratado atualmente de forma relativa e cultural pela historiografia: não podemos associar valores morais aos povos do passado, nem mesmo colocar situações de verdade moral quando tratamos de conflitos ou guerras.

Na Idade Média, os Vikings matavam muitas pessoas e pilhavam diversas localidades européias, mas não adotavam a prática da tortura - amplamente utilizada pelos cristãos. Enquanto os árabes eram vistos como bárbaros desumanos pelos europeus, os muçulmanos ao serem destruídos pelos cruzados faziam exatamente o oposto (DUBY, 1998, p.51-74). São Luíz, o famoso modelo de santidade, teria afirmado a respeito dos árabes: "Com essa gente, há apenas um argumento: a espada. É preciso enfiá-la no seu ventre!". (p. 63). Também os próprios cristãos atacaram outras localidades cristãs, como Constantinopla. Nesse caso, resta aos professores a possibilidade de refletir o comportamento advindo do confronto entre duas culturas distintas (OLIVEIRA, 1993).

Advindo dessa imagem de opositor à civilização, temos o surgimento de outro estereótipo, não tão comum no Brasil quanto na Europa: os Vikings bebendo cerveja e hidromel ${ }^{2}$ nos crânios de seus inimigos. Uma associação direta com o estereótipo do canibalismo, onde o bárbaro ficaria num estado

2 Bebida alcoólica feita à base de mel, típica dos povos escandinavos. 
próximo da bestialidade, incapaz de perpetuar sentimentos humanos típicos dos seres portadores de ordem, moralidade e civilização. ${ }^{3}$ Diversos estudos modernos já demonstraram a inveracidade dessa imagem (ARBMAN, 1967, p. 14).

Mas não é somente em nosso país que as fantasias proliferam pelos meios educacionais ou artísticos. Uma pesquisa efetuada pelo site norueguês The Vikings Network, descobriu que muitas representações falsas proliferam sobre jovens entre 10 e 14 anos do mundo inteiro:

"Ele é um homem com um capacete. Existe chifres em seu capacete. Ele usa roupas de couro. Ele viveu há mil anos atrás." Ingvild (10), Noruega.

"Os Vikings são guerreiros que atacam em seus navios e buscam ouro e tesouros, queimando e matando". Josh (12) NSW, Australia. "Os Vikings foram homens e mulheres que viveram nas costas da Austrália e saíram pelo mar. Vikings travavam batalhas pelo mundo". Chris (11), California, USA.

"Os Vikings tinham a forma dos índios como os Astecas". Katrina (11), California, USA.

Na realidade, o estereótipo acaba circulando de maneira muito intensa na sociedade moderna, numa relação CINEMA + TV + LITERATURA + QUADRINHOS, ocasionando um imaginário muito consistente em jovens adolescentes.

${ }^{3}$ Em diversas situações que vivenciamos, mesmo nos meios universitários, percebemos que existe uma tendência no Brasil em associar a origem do nome da cerveja Skol com esse esterétipo: como a palavra inglesa para crânio e caveira é Skull, muitos acreditam que a antiga prática Viking teria originado a terminologia inglesa e posteriormente, a marca da cerveja. Nada mais incorreto, pois as bebidas entre os bárbaros germânicos eram utilizadas em cornos de animais, e a origem da palavra anglo-saxã Skull provém do nórdico Skoll, uma designação para o deus lobo que perseguia diariamente o Sol (COTTERELL, 1998, p. 226).

História \& Ensino, Londrina, v. 8, p. 85-98, out. 2002 
Recentemente diversas escolas, universidades, museus e fundações culturais elaboraram diversas atividades para tentar reverter as fantasias sobre a cultura escandinava, especialmente nos Estados Unidos e Europa. Porém, as atividades didáticas com o ensino básico ainda são o principal alvo dos pesquisadores para proporcionar uma nova concepção da civilização dos antigos bárbaros (FITZHUGH, 2001; VIKING STEREOTYPE, 2001).

1.1 Panorama do tema em material didático e paradidático no Brasil.

Em nossa análise de livros dirigidos diretamente ao ensino no Brasil, encontramos alguns manuais com os estereótipos em questão.

O primeiro é o manual Nova História Crítica, escrito por Mário Schmidt e dirigido aos alunos de $5^{a}$ série. Na sua página 65 , apresenta uma charge onde um guerreiro Viking de enormes chifres toma violentamente uma mulher - denotando também a imagem dos nórdicos como seres violentos e estupradores. Na mesma obra foi utilizada uma ilustração do século XIX sobre bárbaros (p. 209), perpetuando outro estereótipo clássico, as asas laterais no capacete, muito comuns no personagem infanto-juvenil Asterix e aplicado aos celtas e gauleses. Mais uma fantasia moderna sobre a antigüidade.

Outros livros também apresentam equívocos históricos a respeito dos guerreiros nórdicos:

História $\mathcal{E}$ Consciência do mundo, de Gilberto Cotrim. $1^{\circ}$ grau. Erra ao apresentar uma fotografia de medalhão apontado como germânico, ao tratar das invasões bárbaras do século $\mathrm{V}$ d.C. (p. 129). Trata-se de um medalhão Viking, do século IX$\mathrm{X}$ d.C. Uma figura de guerreiro em tapeçaria foi legendada como Viking (p. 141), mas trata-se de um guerreiro Normando do século XII d.C., detalhe da tapeçaria de Bayeux. 
História Geral, de Gilberto Cotrim. 2ºu. Sobre a religião dos bárbaros germânicos do período das grandes invasões ao império romano - corretamente cita Wodan, Donar e Tiwaz como deuses germânicos (p. 79), mas erra quando cita as Valquírias (nome Viking): o correto seria Idi, e também erra quando cita o Valhala, o paraíso Viking, e Hell, uma espécie de inferno subterrâneo. Entre a cultura germânica continental e a escandinava medieval existem cinco séculos de separação cronológico-espacial, portanto não são a mesma coisa. Os Germanos surgem na História na Antigüidade Tardia e os Vikings durante a Idade Média.

Coleção cultura e sociedade: do homem primitivo até o século XIX, de Maria Valentim e Marileia Ordaz (São Paulo: IBEP, 1999). Apresenta como deuses germânicos do século V d.C.: Odin, Thor, Freia, Valquírias (p. 189), sendo que na realidade eles são expressões lingüísticas de deuses Vikings durante a Idade Média.

Temos que perceber que o espaço dedicado exclusivamente aos escandinavos medievais nos manuais de ensino fundamental e médio é extremamente curto, ocasionando uma ausência de iconografia e consequentemente, maiores condições de análise por nossa parte.

Alguns manuais paradidáticos atualmente disponíveis no Brasil, em sua maioria traduções de originais estrangeiros, são de excelente qualidade: Vikings (Coleção "Desafios",1996), Fiona MacDonald; Os Vikings (Coleção "Povos do passado",1990), Michael Gibson; Os Vikings (Coleção "Povos do passado",1996), Philippe Brochard; Os Vikings (Coleção "Eu estive lá",1993), John Clare. Com textos acessíveis, documentados e fartamente ilustrados, são um excelente apoio didático aos professores de ensino fundamental e médio, principalmente para criarem condições de reverter as imagens estereotipadas. 
Entretanto, uma edição paradidática apresentou uma farta iconografia estereotipada: Os Vikings (Coleção "Mitos e Lendas", 1997), Gilles Ragache. De origem francesa, o texto apresenta uma adaptação infanto-juvenil de muitos mitos de origem germânica, mas que acabam perpetuando as imagens tradicionais sobre o bárbaro por meio das diversas ilustrações que acompanham o texto.

Outro livro que apresenta muitos problemas é $\mathrm{O}$ enigma dos Vikings (Coleção "Entre Linhas e Letras", 1999), de Romilda Raeder. Trata-se de um romance destinado ao público infantil do ensino fundamental. Os escandinavos são tratados no livro como seres extremamente embrutecidos, enormes, musculosos e muito violentos. Ou seja, um referencial moderno advindo de filmes como Conan, o Bárbaro. A ilustração da capa já esclarece o conteúdo: um brutamonte com o típico capacete de cornos.

Em mais uma obra destinada ao público infanto-juvenil, desta vez um desenho animado, As novas aventuras de Robin Hood (Coleção "Videoteca da criança", 1992) também exemplifica o poder do estereótipo. $\mathrm{Na}$ Inglaterra medieval, o povo vive pacificamente sob o comando do herói Robin Hood, até o momento em que os Vikings surgem, matando e destruindo a harmonia coletiva. Aqui temos uma típica associação de VIOLÊNCIA + CHIFRES = BARBÁRIE, que influi muito na construção do imaginário das crianças e adolescentes.

\section{Estudo de caso: desmistificação dos Vikings no ensino médio}

Em outubro de 2001 efetuou-se um estágio supervisionado do curso de História da Unespar, campus de 
União da Vitória, tratando da desmistificação dos povos escandinavos. $\mathrm{O}$ estágio foi executado no estabelecimento Colégio Estadual Neusa Domit, na cidade de União da Vitória, PR. A turma escolhida foi a primeira série do ensino médio, composta por 30 alunos, tendo como supervisores os professores Leni Trentin Gaspari e Aluísio Witiuk, e como estagiário o estudante Marlon Ângelo Maltauro.

O principal objetivo do estágio era a ruptura das idéias préconcebidas referentes aos escandinavos medievais, bem como a exposição do seu legado, com o intuito de criar reflexões acerca dos acontecimentos históricos (MALTAURO, 2001, p. 34).

Os conteúdos explorados foram: origem da civilização Viking; cultura; organização político-administrativa; arquitetura e escultura; religião e mitologia; o fim da era Viking.

Com relação às principais competências e habilidades propostas:

- Localizar no mapa mundi os países de origem dos povos Vikings, os países por eles colonizados e as rotas de suas incursões pelo mundo.

- Situar as diversas produções da cultura nórdica - as linguagens, as artes, a religião, a mitologia, as tecnologias e outras manifestações - nos contextos históricos de suas constituição e significação.

- Comparar problemáticas atuais com o período abordado nas aulas.

- Demonstrar o tempo histórico como duração.

- Criticar, analisar e interpretar fontes documentais de naturezas diversas.

- Produzir textos analíticos e interpretativos sobre este processo histórico. 
Durante a primeira aula, após a apresentação do tema e os objetivos do estágio, foi solicitado aos alunos que desenvolvessem um texto sobre qual era a sua concepção a respeito dos Vikings. Praticamente a maioria tratou da imagem clássica, o estereótipo do qual abordamos até aqui (MALTAURO, 2001, p. 34-37). Após a produção textual, explicou-se como foram originados os estereótipos e imagens fantasiosas e em seguida foram abordados os aspectos básicos do mundo nórdico. Por meio de mapas, gráficos e recursos visuais, explanou-se sobre a cultura Viking desde suas origens até o período de expansão. As principais características da sociedade, política, comércio, colonização e principais descobertas arqueológicas da atualidade.

$\mathrm{Na}$ segunda aula foi exibido o filme $\mathrm{O}$ décimo terceiro guerreiro, produção cinematográfica recente que retrata com muito realismo a cultura Viking. Também foram feitos comentários sobre o enredo do filme, baseado nas expedições do árabe Ahammed Ibn Fadlan, além de discussão com os alunos aos final da transmissão do vídeo.

$\mathrm{Na}$ terceira e última aula foi exibido o documentário Os Vikings, onde os alunos fizeram a comparação com o conteúdo e o filme exibido anteriormente. E como trabalho final, foi solicitado aos estudantes que novamente escrevessem o que pensavam sobre os escandinavos medievais.

Os resultados alcançaram a proposta inicial do projeto de estágio, demonstrando a possibilidade de se reverter estereótipos da História:

"Eu imaginava que os Vikings eram, quer dizer, usavam capacetes com chifres, que eram muito brutos com as mulheres, e que principalmente não tinham um lugar para habitar, que eram um povo nômade" (Elis Ângela). 
"Não é aquele homem com um chifre na cabeça como muitos entendiam como Viking". (Adriely de Brito).

"É uma visão bem diferente, que eles eram pessoas porcas e que usavam chifres na cabeça [...] Até que eles eram pessoas bem unidas" (Natali Moreira da Cruz).

"Mudei muito a minha maneira de ver os Vikings, eles não são apenas homens que se vestem mal, ou porcos como antes eu coloquei. São ou foram acima de tudo homens corajosos, lutadores, sonhadores, sonhavam com um mundo melhor" (Elaine).

\section{Conclusão: História e ensino reflexivo}

Ao analisar a metodologia de ensino tradicional podemos verificar que em muitos casos é uma forma pedagógica ultrapassada, necessitando rapidamente de alterações. Nestas metodologias percebemos que o ensino da História mostra-se como produto pronto e acabado, verdades absolutas trazidas pelos professor que orienta-se pelo livro didático e repassa esse conteúdo. Dessa maneira, imagens tradicionais, produtos do senso comum e muitos estereótipos são perpetuados constantemente nas mais diversas escolas e faculdades de nosso país. Mas a reflexão crítica sobre as imagens canônicas (SALIBA, 1999) ou estereótipos no ensino de História também deve partir dos próprios alunos:

"Devemos fazer com que o aluno construa seu próprio conhecimento. Para que isto ocorra o educador deve estimular debates em sala de aula e fazer com que o aluno produza textos, manifestando a compreensão do que leu, com o que o professor falou e discutiu em sala de aula, estabelecendo relações. No tocante a esta produção histórica o educador também deve fazer com que ela tenha a finalidade de captar e recuperar as relações que se estabelecem entre os grupos humanos, que sempre em. desenvolvimento, evidenciam manifestações contraditórias" (MALTAURO, 2001, p. 49). 
Em um outro experimento didático desenvolvido sobre o tema dos Vikings, percebemos do mesmo modo a importância da reflexão dos alunos, levando-os a situar o debate sobre o estereótipo do bárbaro para o mundo contemporâneo:

"Nestas discussões, as classes refletiram sobre a discriminação sofrida por negros e índios em diversas épocas e países, lembraram a maneira como os europeus ocidentais vêem seus compatriotas do leste. E, no final, alguns alunos chegaram à conclusão de que, para muita gente, o "bárbaro" de ontem é o nordestino, ou "baiano", de hoje" (OLIVEIRA, 1993).

O surgimento do bárbaro idealizado durante o século XIX atendia a motivações que iam além do interesse individual dos artistas. Foi fruto de um momento onde o mito explicava as origens históricas e era legitimado pela linguagem artística. Em nosso tempo apenas restou o estereótipo, que cada vez mais cede espaço para novas interpretações artísticas e produtos da cultura de massa. A imagem dos Vikings ainda continua a fascinar, restando aos educadores, pesquisadores e estudantes o resgate de uma nova forma de conceber esses povos do passado, tornando o ensino de História muito mais reflexivo. Afinal, como declarou Robert Darton, uma das missões do historiador é dar sentido à condição humana. Ao desconstruir estereótipos, nós estaremos não somente entendendo de maneira muito mais eficiente as antigas sociedades, como também refletindo sobre nosso próprios valores contemporâneos. 


\section{Referências Bibliográficas}

ALMEIDA, Juliana; BARRALES, Luciana; TRUSIEWICZ, Tatiana. O racismo nos livros didáticos. Trabalho apresentado à disciplina Edição de Livros Didáticos e Paradidáticos, do departamento de Jornalismo e Editoração da USP. São Paulo, 1999.

ARBMAN, Holger. Os Vikings. Lisboa: Editorial Verbo, 1967.

BROCHARD, Philippe ; KRAHENBUHL, Eddy. Os Vikings: senhores dos mares. São Paulo: Augustus, 1996.

CLARE, John. Vikings. São Paulo: Manole, 1993.

COTRIM, Gilberto. História $\mathcal{E}$ Consciência do mundo. São Paulo: Saraiva, 5 ㄹe edição, 1994.

História Geral. São Paulo: Saraiva, 3a. edição, 1993.

DUBY, Georges. Ano 1000/Ano 2000: na pista de nossos medos. São Paulo: Unesp, 1998.

FITZHUGH, William W. Battling the dominant stereotype. Vikings arrive in America - Again! The American Scandinavian Fundation, 2001. http:// www.amscan.org/viking.html

GIBSON, Michael. Os Vikings. São Paulo: Melhoramentos, 1990.

LANGER, Johnni. A origem do imaginário sobre os Vikings. Espaço Plural, Unioeste/Cepedal, ano III, n. 8, agosto 2001.

Guia de Vikings Sobresites, Rio de Janeiro, 2002.

http://www.sobresites.com/VIKINGS/

Vikings in Brazil. Viking Saga, Madrid, 2002.

http://perso.wanadoo.es/mwb/ing/colab.htm

Guia bibliográfico e videográfico sobre os Vikings em português. Guia de Vikings Sobresites, Rio de Janeiro, 2002. http://www.sobresites.com/ vikings/artigos.htm

O lado cômico da cultura Viking. Aesgaard: mitologia, cultura e religião nórdica, São Paulo, 2002. http://www.aesgaard.com/ osvikings.php?artigolD $=9$ 
Vikings e fenícios antes de Colombo: fraudes epigráficas e mitos arqueológicos nas Américas. Guia de Vikings Sobresites, Rio de Janeiro, 2002. http://www.sobresites.com/vikings/artigos.htm

MACDONALD, Fiona. Vikings. São Paulo: Moderna, 1996.

MALTAURO, Marlon Ângelo. A civilização Viking: desmistificação do povo nórdico. Trabalho final de estágio supervisionado apresentado à disciplina de prática de ensino de História, curso de História da Unespar. União da Vitória, outubro de 2001.

OLIVEIRA, Elvira. Vikings e Saxões invadem São Paulo e ajudam alunos a pesquisar com gosto. Nova Escola, v. 8, set. 1993.

RAEDER, Romilda. O enigma dos Vikings. São Paulo: Atual Editora, 1999.

RAGACHE, Gilles ; LAVERDET, Marcel. Os Vikings: mitos e lendas. São Paulo: Ática, 1997.

RAMINELLI, Ronald. Bárbaros e colonizadores. In: Imagens da colonização. Rio de Janeiro: Zahar, 1996.

SALIBA, Elias Thomé. As imagens canônicas e o ensino de História. In: III encontro Perspectivas do Ensino de História. Curitiba: Aos Quatro Ventos, 1999.

SCHMIDT, Mário. Nova História Crítica. São Paulo: Nova Geração, 2001.

SILVA, Marcos A. da. História: o prazer em ensino e pesquisa. São Paulo: Brasiliense, 1995.

THE VIKINGS NETWORK. http://viking.no/

VIKINGS STEREOTYPE VIEWS. The moderns myths, Project Beowulf, 2001. http://www.intercollege.se/viking/mythology $1 /$ myths.htm

ABSTRACT:

The article looks for to reflect on the Barbarian in the education of History, considering some elements for the critical of stereotypes.

KEY-WORDS:

Viking civilization, stereotype, education of History. 